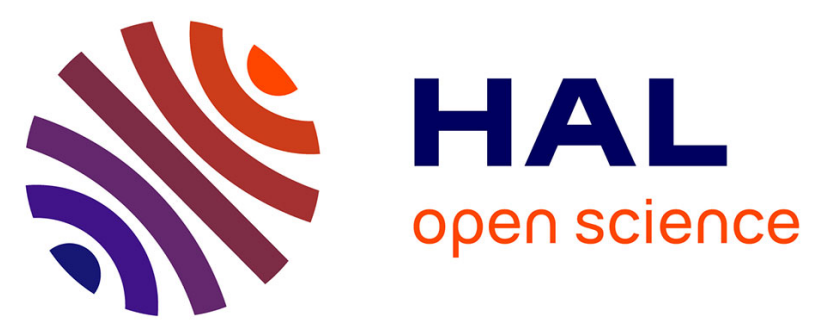

\title{
Investigation of squalene-doxorubicin distribution and interactions within single cancer cell using Raman microspectroscopy
}

\author{
Hassan Rammal, Almar Al Assaad, Franco Dosio, Barbara Stella, Andrei \\ Maksimenko, Simona Mura, Laurence van Gulick, Maïté Callewaert, Didier \\ Desmaële, Patrick Couvreur, et al.
}

\section{To cite this version:}

Hassan Rammal, Almar Al Assaad, Franco Dosio, Barbara Stella, Andrei Maksimenko, et al.. Investigation of squalene-doxorubicin distribution and interactions within single cancer cell using Raman microspectroscopy. Nanomedicine: Nanotechnology, Biology and Medicine, 2021, 35, pp.102404. 10.1016/j.nano.2021.102404 hal-03406418

\section{HAL Id: hal-03406418 \\ https://hal.science/hal-03406418}

Submitted on 27 Oct 2021

HAL is a multi-disciplinary open access archive for the deposit and dissemination of scientific research documents, whether they are published or not. The documents may come from teaching and research institutions in France or abroad, or from public or private research centers.
L'archive ouverte pluridisciplinaire HAL, est destinée au dépôt et à la diffusion de documents scientifiques de niveau recherche, publiés ou non, émanant des établissements d'enseignement et de recherche français ou étrangers, des laboratoires publics ou privés. 


\section{Investigation of squalene-doxorubicin distribution and interactions within single cancer cell using Raman microspectroscopy}

Hassan Rammal ${ }^{1, \Omega, \mathbb{I}}$, Almar Al Assaad ${ }^{1, \Omega}$, Franco Dosio ${ }^{2}$, Barbara Stella ${ }^{2}$, Andrei Maksimenko $^{3}$, Simona. Mura ${ }^{3}$, Laurence Van Gulick ${ }^{1}$, Maïté Callewaert ${ }^{4}$, Didier Desmaële ${ }^{3}$, Patrick Couvreur $^{3}$, Hamid Morjani ${ }^{1 \#}$, Abdelilah Beljebbar ${ }^{1 \#^{*}}$

1. Translational BioSpectrocopy, BioSpecT, EA 7506, Université de Reims, Faculté de Pharmacie, Reims, France

2. Department of Drug Science and Technology, University of Torino, 10125 Torino, Italy

3. Institut Galien Paris-Saclay CNRS UMR8612, Université Paris-Saclay, Faculté de Pharmacie, Châtenay-Malabry, France.

4. Institut de Chimie Moléculaire de Reims, ICMR - UMR 7312, Université de Reims, Faculté de Pharmacie, Reims, France

${ }^{\Omega} \mathrm{H}$ R. and A A contributed equally to this work

${ }^{\#}$ H M. and A B co-supervised this work

${ }^{\mathbb{I}}$ Present adress : EFOR Healthcare Paris, Biocompatibility Platform, 92300 Levallois-Perret, France.

*: Correspondence should be sent to:

Dr. Abdelilah BELJEBBAR

Translational BioSpectrocopy, EA 7506

UFR de Pharmacie

Université de Reims Champagne-Ardenne

51, rue Cognacq-Jay,

51096 Reims CEDEX, France

Phone: (33) $32691-8376$

Fax: (33) 3 2691-8282

E-mail: $\quad$ abdelilah.beljebbar@univ-reims.fr 


\begin{abstract}
Intracellular distribution of doxorubicin (DOX) and its squalenoylated (SQ-DOX) nanoparticles (NPs) form in murine lung carcinoma M109 and human breast carcinoma MDA-MB-231 cells were investigated by Raman microspectroscopy. Pharmacological data showed that DOX induced higher cytotoxic effect than SQ-DOX NPs. Raman data were obtained using single-point measurements and imaging on the whole cell areas. These data showed that after DOX treatment at $1 \mu \mathrm{M}$, the spectral features of DOX were not detected in the M109 cell cytoplasm and nucleus. However, the intracellular distribution of SQ-DOX NPs was higher than DOX in the same conditions. In addition, SQ-DOX NPs were localized into both cell cytoplasm and nucleus. After $5 \mu \mathrm{M}$ treatment, Raman bands of DOX at 1211 and $1241 \mathrm{~cm}^{-}$were detected in the nucleus. Moreover, the intensity ratio of these bands decreased, indicating DOX intercalation into DNA. However, after treatment with SQ-DOX NPs, the intensity of these Raman bands increased. Interestingly, with SQ-DOX NPs, the intensity of $1210 / 1241 \mathrm{~cm}^{-1}$ ratio was higher suggesting a lower fraction of intercalated DOX in DNA and higher amount of non-hydrolyzed SQ-DOX. Raman imaging data confirm this subcellular localization of these drugs in both M109 and MDA-MB-231 cells. These finding brings new insights to the cellular characterization of anticancer drugs at the molecular level, particularly in the field of nanomedicine.
\end{abstract}

Key words: Raman microspectroscopy; cancer cells, squalenoylated doxorubicin, nanoparticles 


\section{Introduction}

Cancer treatment is often limited by a lack of selectivity and toxicity(1,2). Doxorubicin (DOX) emerged as one of the most widely used anti-cancer chemotherapeutic drug $(3,4)$. Generally, it is accepted that DOX has the ability to intercalate between the G-C base pairs $(5,6)$ and to inhibit DNA topoisomerase II resulting in inhibition of DNA replication and cell growth (7-9). Unfortunately, the use of DOX in clinic encounters some limitations, including a lack of selectivity, cardiotoxicity and development of resistance $(5,10,11)$.

One of the used strategies to improve antitumor efficacy, tissue distribution and pharmacokinetics of anticancer drugs is the development of nanoscale drug delivery systems (i.e. nanomedicine) (12). In this context, various nanocarriers of DOX have been developed (13-15). Recently, the chemical linkage of DOX to squalene (SQ), a natural lipid precursor of the cholesterol's biosynthesis, has been proposed (16). Such bioconjugate (SQ-DOX) was found to spontaneously self-assemble in water in form of nanoparticles (NPs) of 130-nm mean diameter. In vivo, SQ-DOX NPs were found to reduce murine pancreatic tumor growth by $95 \%$, compared to only a $29 \%$ DOX. In M109 murine lung carcinoma, a $90 \%$ tumor inhibition was observed SQ-DOX NPs, whereas DOX was ineffective. In addition, SQ-DOX NPs were five-fold better tolerated than DOX, thus significantly reducing both cardiac and digestive toxicities (16).

A better understanding of the mechanism behind the observed anticancer efficacy, including cellular uptake, intracellular distribution and subcellular interactions is crucial to improve the benefit/risk ratio of this approach. Interestingly, near infrared Raman microspectroscopy emerged as an attractive label-free and a non-invasive methodology for monitoring the molecular information associated with the biological activity of anticancer agents (17-19). This technique has been previously used to analyze biochemical information simultaneously on both the drug and the cell components (i.e. DNA, RNA, proteins, and lipid content) (20- 
23). Additionally, Raman spectroscopy has the ability to study cells in physiological conditions with high spatial resolution (24). Several studies have already investigated the effect of DOX and its interaction with DNA at the molecular and cellular levels using Raman spectroscopy $(22,25-31)$. This technique was also used for preclinical applications such as the quantification of antineoplastic drugs in the tumor (32), and the screening of early stage cellular response to different drug treatments for improving drug efficacy and reducing toxicity $(32-35)$.

Herein, we shed light on the potential use of Raman microspectroscopy to investigate the intracellular distribution and interaction of DOX and SQ-DOX NPs in cytoplasmic and nuclear compartments of murine lung carcinoma (M109) and human breast carcinoma (MDAMB-321) cell lines in vitro.

\section{MATERIALS AND METHODS}

\section{Drugs}

DOX was purchased from Sigma-Aldrich (Saint-Quentin Fallavier, France). The chemical structure of DOX consists of a tetracyclic ring with the sugar daunosamine attached by a glycosidic linkage. SQ was purchased from Sigma-Aldrich. This molecule is a polyunsaturated hydrocarbon of the triterpene type. SQ-DOX was synthesized by chemical linkage of the anticancer drug DOX onto SQ (16). SQ-DOX NPs were prepared using the nanoprecipitation method. Briefly, $500 \mu \mathrm{L}$ of a tetrahydrofuran solution of SQ-DOX (4 $\mathrm{mg} / \mathrm{mL}$ ) was added drop-wise under stirring $(500 \mathrm{rpm})$ into $1 \mathrm{~mL}$ distilled water. Precipitation of the SQ-DOX NPs occurred spontaneously after evaporation of tetrahydrofuran. The diameter of the nanoparticles was determined by laser light scattering at $20{ }^{\circ} \mathrm{C}$ using a nanosizer (Zetasizer Nano ZS, Malvern Instrument, UK).

\section{Cancer cell culture}


The murine lung carcinoma (M109) and human breast cancer MDA-MB-231 cell lines were maintained as recommended. Briefly, M109 and MDA-MB231 cells were cultured in RPMI medium 1640 and DMEM respectively supplemented with $10 \%$ heat-inactivated fetal bovine serum (FBS), penicillin $(100 \mathrm{U} / \mathrm{mL})$ and streptomycin $(100 \mu \mathrm{g} / \mathrm{mL})$. Cells were kept in a humidified atmosphere of $5 \% \mathrm{CO}_{2}$ with a medium change every two days and were routinely passaged at pre-confluency using $0.05 \%$ trypsin, $0.53 \mathrm{mM}$ EDTA (Invitrogen) and screened for the absence of mycoplasma using PCR methods.

\section{Cytotoxicity assay}

M109 cells at $5 \times 10^{4}$ cells $/ \mathrm{ml}$ density were allowed to adhere on 24 well plate for $24 \mathrm{~h}$ at 37 ${ }^{\circ} \mathrm{C}$ in a humidified atmosphere of $5 \% \mathrm{CO}_{2}$ in air. After pre-incubation, cells were washed with sterile phosphates-buffered saline (PBS) and then exposed to series of concentrations of free DOX or SQ-DOX NPs ranging from $0.1 \mathrm{nM}$ to $1 \mu \mathrm{M}$ for $72 \mathrm{~h}$. Non treated cells were used as control. For short time drug exposure, cells were exposed to series of concentrations of free DOX or SQ-DOX ranging from $0.1 \mu \mathrm{M}$ to $50 \mu \mathrm{M}$ for $1 \mathrm{~h}$. After the short time incubation, the culture medium containing the drug was removed, cells were then washed and incubated with a new culture medium for $72 \mathrm{~h}$. Afterwards, in both protocols, cells were then washed and detached using $0.05 \%$ trypsin, $0.53 \mathrm{mM}$ EDTA and counted using a traditional cell Kova ${ }^{\circledR}$ slide counting plate (Kova international). The inhibitory concentration 50\% ( $\left.\mathrm{IC}_{50}\right)$ was defined as the drug (DOX or SQ-DOX) concentration required to inhibit M109 cell growth by 50\%, relative to untreated controls. $\mathrm{IC}_{50}$ values were estimated from the dose response curves plotted using GraphPad Prism ${ }^{\circledR} 6$ software and provided from the average of three different experiments and in duplicate at each time.

\section{Annexin V and Caspase 3/7 analysis}

M109 cells at $10^{5}$ cells $/ \mathrm{ml}$ density were allowed to adhere on six well plate for $24 \mathrm{~h}$ at $37^{\circ} \mathrm{C}$ in a humidified atmosphere of 5\% CO2 in air. After pre-incubation, cells were then washed 
with sterile PBS and incubated for $48 \mathrm{~h}$ with free DOX or SQ-DOX NPs at the concentration of $100 \mathrm{nM}$. After treatment, cells were harvested using trypsin-EDTA, washed two times with PBS, and re-suspended in fresh culture medium containing $10 \%$ serum. Cell suspensions were stained using the Muse ${ }^{\mathrm{TM}}$ Annexin V and Caspase 3/7 kit (Millipore, Molsheim, France) according to manufacturer's instructions. Data were acquired on a Muse ${ }^{\mathrm{TM}}$ Cell Analyzer (Millipore, Molsheim, France).

\section{Cellular drug distribution by confocal fluorescence microscopy}

M109 and MDA-MB-231 cells were seeded on $\mathrm{CaF}_{2}$ substrates, placed in petri dishes, to achieve $40-60 \%$ confluence after $24 \mathrm{~h}$ at $37{ }^{\circ} \mathrm{C}$ in a humidified atmosphere of $5 \% \mathrm{CO}_{2}$ in air. Cells were then washed with sterile PBS and incubated at $37^{\circ} \mathrm{C}$ with free DOX or SQ-DOX NPs at the concentrations of $1 \mu \mathrm{M}$ for 1 hour and $5 \mu \mathrm{M}$ for 1 and 5 hours. After treatment, cells were washed with PBS and fixed using PFA (4\%), they were then analyzed by fluorescence microscopy (Zeiss) equipped with 63X oil immersion objective and Raman microsproscopy. The fluorescence of DOX was measured using excitation at $488 \mathrm{~nm}$ and emission at $560 \mathrm{~nm}$. We then quantified the cellular accumulation of DOX and SQ-DOX from the analysis of fluorescence images using Open source NIH ImageJ software (Wayne Rasband, National Institutes of Health, Bethesda, MD). Briefly, regions-of-interest (ROIs) were selected in each nucleus by ImageJ. The average fluorescence intensity was determined in each ROI, for DOX and SQ-DOX NPs.

\section{Raman microspectroscopy}

Raman spectra were recorded with a near infrared confocal Raman spectrometer (Labram ARAMIS, Horiba Jobin Yvon S.A.S., France). This setup consisted of a microscope (Olympus, BX41, France) coupled to the Raman spectrometer equipped with 600 groove/mm diffraction grating. The microscope was equipped with a xy-motorized (Marzhauser, Germany), computer-controlled sample stage, which enabled automatic scanning of the 
sample with a spatial resolution of $1 \mu \mathrm{m}$. The excitation source $(785 \mathrm{~nm})$ was provided by diode laser (Toptica Photonics, Germany) delivering $60 \mathrm{~mW}$ of laser power on the sample. This laser excitation was focused on the single cell with water immersion NIR 100x objective (NA 1.0, Olympus, France). This backscattered light was collected by the objective and was transmitted to the spectrometer equipped with a Pelletier-cooled charge-coupled device detector. M109 cells and MDA-MB-231 (50. $10^{3}$ cells/mL /window) were seeded on previously sterilized $\mathrm{CaF}_{2}$ windows in 6-well plate $24 \mathrm{~h}$ before treatment. Cells were incubated with or without DOX or SQ-DOX NPs at concentrations of 1 and $5 \mu \mathrm{M}$ and placed into petri dishes for $1 \mathrm{~h}$ and $5 \mathrm{~h}$. After incubation, medium was then removed and cells were rinsed twice with sterile PBS. Cells were kept in PBS for Raman acquisition. Spectra were acquired on five different cells. For each cell, 15 measurements were performed at two different cell compartments: nucleus and cytoplasm, using a 20 seconds integration time in the $600-1800 \mathrm{~cm}^{-1}$ spectral region with a spectral resolution of $4 \mathrm{~cm}^{-1}$. Raman spectral images were recorded on single fixed M109 and MDA-MB-231 cells non treated and treated with DOX and SQ-DOX at concentration of $5 \mu \mathrm{M}$ for $1 \mathrm{~h}$ and $5 \mathrm{~h}$. These images were acquired with the same experimental conditions than single point measurements with spatial resolution of 1 $\mu \mathrm{m}$.

Data acquisition was carried out by means of the LabSpec 5 software (Horiba Jobin Yvon S.A.S. France).

\section{Data pretreatment}

Various data processing were performed on these measured data (36). After acquisition, spectra were first calibrated using Raman calibration standards. The spectrum of the halogen lamp was used to correct for the wavelength-dependent signal detection efficiency of the Raman setup. Raman data were analyzed with custom software developed in MatLab (MathWorks, Inc., Matick, USA). All spectra were corrected for the interference background, 
baseline corrected using a fourth order polynomial and smoothed with fifth points SavitzkyGolay algorithm in order to minimize the influence of noises. The resulting spectra were then normalized using a Standard Normal Variate (SNV) procedure (37).

Principal component analysis (PCA) was used on spectral imaging data to identify the independent sources of variation in all spectra and to reduce the number of variables describing the dataset. This procedure allowed the identification of the subsets of data that may be associated to different drug treatments. Prior to the analysis, dataset was divided into two groups according to the two different drugs. PCA was performed on each sub-dataset. PCs potentially attributed to DOX or SQ-DOX were used to construct pseudo-colors score maps. All processing on Raman spectral images was performed with Matlab (Version 9.4, MathWorks, Inc., Matick, USA).

\section{Statistical analysis}

ANOVA test was performed using GraphPad Prism 6 software. Statistical significance was assessed by followed by Sidak simple comparison test $\left({ }^{*} \mathrm{p}<0.05, * * * \mathrm{p}<0.001\right)$.

\section{RESULTS}

\section{Antitumor activity of DOX and SQ-DOX}

In order to evaluate DOX and SQ-DOX NPs antitumor activity, M109 cells were preincubated for $24 \mathrm{~h}$ and then exposed to concentrations of DOX and SQ-DOX NPs ranging from $0.1 \mathrm{nM}$ to $1 \mu \mathrm{M}$. Dose-response assays plots allowed to calculate the drug concentration, which induces $50 \%$ cell growth inhibition $\left(\mathrm{IC}_{50}\right)$. After long-term treatment, DOX and SQDOX NPs inhibited the growth of M109 cells in a concentration-dependent manner and the calculated $\mathrm{IC}_{50}$ were respectively 2.6 and $18 \mathrm{nM}$ (Figure 1a, table 1). After short-term treatment, DOX and SQ-DOX NPs induced also a decrease in cell growth with $\mathrm{IC}_{50}$ values of 0.12 and $1.2 \mu \mathrm{M}$, respectively (Figure $1 \mathrm{~b}$, table 1 ). To investigate the drug-induced apoptosis, M109 cells were treated with DOX or SQ-DOX NPs at concentration of $100 \mathrm{nM}$. After $48 \mathrm{~h}$ 
incubation, Annexin-V staining revealed that SQ-DOX treatment induced $45 \%$ apoptosis, whereas DOX treatment induced $75 \%$ positive (Figure 1C) $(p<0.001)$. These results were concomitant with caspase $3 / 7$ staining, a hallmark of the apoptosis induction, showing a higher caspase $3 / 7$ activation upon DOX treatment with $43 \%$ of positive cells compared to only 30\% upon SQ-DOX treatment $(p<0.05)$ (Figure 1d). While in vivo SQ-DOX treatment markedly inhibited M109 tumors (90\% with SQ-DOX vs 3\% with DOX) demonstrating the efficacy of this nanomedicine even in a drug-resistant tumor model, the in vitro results failed to highlight such effects (16). This inconsistency is rather usual in the nanomedicine field, due to the slow release of the parent drug from SQ-DOX nanoparticles and to their improved pharmacokinetic (i.e. reduced clearance), reduced elimination and tumor specific biodistribution.

\section{Cellular drug distribution}

To investigate cellular distribution of the drugs using confocal fluorescence microscopy, M109 and MDA-MB-231 cells were first treated with DOX or SQ-DOX NPs at a concentration of $1 \mu \mathrm{M}$ during $1 \mathrm{~h}$ (figure 2). The red fluorescence emission corresponds to the drugs. To better appreciate the localization of DOX and SQ-DOX NPs in the different cellular compartments, drug fluorescence images were merged with transmission microscopy images. As shown in the first and the fourth columns, fluorescence emission was predominantly localized in the cell nucleus in the case of DOX treatment for both M109 and MDA-MB-231 cells, whereas after SQ-DOX NPs treatment, fluorescence emission was localized both in the cytoplasm and the nucleus. Since a correlation has been previously established between nuclear uptake of DOX and its cytotoxic effect $(38,39)$, fluorescence emission intensity from the nucleus has been evaluated (figure 3). As shown, there was no significant difference in terms of fluorescence emission intensity in the nucleus between DOX and SQ-DOX NPs treatments for both cell lines; (figure 3). Cells were then treated with $5 \mu \mathrm{M}$ 
of DOX or SQ-DOX NPs for respectively 1 and 5h. In the case of DOX treatment, drug fluorescence emission was still predominantly localized in the nucleus for both 1 and $5 \mu \mathrm{M}$ treatments (figure 2). Moreover, the intensity of fluorescence emission increased when compared to $1 \mu \mathrm{M}$ treatment during $1 \mathrm{~h}$ in both cell lines (figure 3 ). In the case of SQ-DOX NPs treatment at $5 \mu \mathrm{M}$ for $1 \mathrm{~h}$, fluorescence emission was still localized in both cytoplasm and nucleus as show in figure 2 (second and fifth columns) with an increase of the intensity of fluorescence emission from the nucleus (figure 3). A similar distribution was observed in the case of the treatment for 5 hours as shown in figure 2 (third and 6th columns) with an increase in the intensity of fluorescence emission from the nucleus compared to the treatment for 1 hour (figure 3).

\section{Investigation of DOX and SQ-DOX NPs cellular uptake and distribution by Raman microspectroscopy}

Raman microspectroscopy was used to track DOX and SQ-DOX NPs at the subcellular level (nucleus and cytoplasm) and to distinguish, at the molecular level, the two forms of the drug and their effects on the cellular components. The Chemical structures of DOX, SQ, and SQDOX were displayed in figure $4 a, 4 b$ and $4 c$ respectively. Figure $4 d$ shows their average Raman spectra in solution. Raman spectrum of free DOX exhibited the main characteristic bands originated from the conjugated aromatic chromophore of the drug (substituted rings A, B and C) (25). Table II listed the frequencies and tentative Raman bands assignments of DOX (27). The spectrum of SQ-DOX NPs was dominated by the molecular signature of DOX (Figure 4d). The main changes in Raman signature of SQ-DOX NPs were associated to a decrease in the intensity of the band at $1210 \mathrm{~cm}^{-1}$ and the presence of an additional band at $1669 \mathrm{~cm}^{-1}$, which was attributed to SQ. These changes are related to the chemical linkage between SQ and DOX. The main band in the Raman spectrum of SQ at $1669 \mathrm{~cm}^{-1}$ was attributed to the symmetric stretching of the six double bonds in the compound. The other 
bands located in the region $1250-1400 \mathrm{~cm}^{-1}$ were attributed to various skeletal stretching and bending modes $\left(\mathrm{CH}_{2} / \mathrm{CH}_{3}\right.$ bending, $\omega(\mathrm{CH})$ wag (in-plane), and $\gamma(\mathrm{C}-\mathrm{C})$ stretching) (40).

Raman microspectroscopy was first used to investigate the effects of both DOX and SQ-DOX NPs at two concentrations ( 1 and $5 \mu \mathrm{M})$ on the components in the cytoplasm and the nucleus of M109 living single cell after $1 \mathrm{~h}$ treatment (Figure 5). The average spectra were shown with their spectral variability. The spectra of untreated cells displayed common Raman bands associated to proteins and/or lipids, and nucleic acids (Figure 5A). Band assignments of Raman spectra of human cell lines are presented in Table 2. Cells were then treated with DOX and SQ-DOX NPs, and difference spectra were calculated by subtracting mean Raman spectra measured in the nucleus of control untreated cells from spectra measured in the nucleus of treated cells, to better understand the effects of DOX and SQ-DOX NPs on the cellular components. These difference spectra (b-a and c-a) revealed positive peaks that gave an estimation of the molecular species highlighted in treated cells as compared to the control ones. These difference spectra were superimposed with Raman spectrum of DOX in solution (Figure 5A). The difference in spectrum (b-a) did not allows the identification of DOX features due to the low concentration of DOX treatment at $1 \mu \mathrm{M}$. However, negative peaks observed in the difference spectrum at frequencies of $782 \mathrm{~cm}^{-1}(\mathrm{O}-\mathrm{P}-\mathrm{O}$ stretching mode of DNA backbone), $1100\left(\mathrm{PO}^{2-}\right.$ stretching mode of the DNA), $1372 \mathrm{~cm}^{-1}$ (thymine), 1484, and $1575 \mathrm{~cm}^{-1}$ (adenine and guanine) were assigned to nucleic acids content. These data are in agreement with the expected changes in nucleus, probably related to the mechanism of action of the drug. However, at $5 \mu \mathrm{M}$, the difference spectrum (c-a) showed positive bands at 1084, $1210,1241,1302$, and $1443 \mathrm{~cm}^{-1}$ associated to DOX features (Figure 5A). DOX bands at $1210,1241 \mathrm{~cm}^{-1}$ were used as marker of its uptake in the nucleus. The intensity of 1210/1241 $\mathrm{cm}^{-1}$ ratio related to DOX in the nucleus decreased compared to free DOX, indicating intercalation of DOX in DNA. In addition, bands 1003, 1451 and $1661 \mathrm{~cm}^{-1}$ displayed were 
attributed to protein. The band at $1451 \mathrm{~cm}^{-1}$ corresponds to the contribution of both $\mathrm{CH}_{2}$ deformation mode arising from proteins and DOX peak. These data suggested that the increase in the concentration of DOX, from 1 to $5 \mu \mathrm{M}$, resulted in a higher accumulation of nuclear DOX.

We then investigated the effects and the cellular distribution of SQ-DOX NPs in M109 cells Figure 5B shows Raman spectra from nucleus of untreated and treated cells with SQ-DOX NPs. These spectra exhibited Raman bands similar to those observed and attributed in Figure 5A. In the difference spectrum (b-a) (Figure 5B), which corresponded to $1 \mu \mathrm{M}$ SQ-DOX NPs treatment, we have identified the two SQ-DOX bands at 1210 and $1241 \mathrm{~cm}^{-1}$. The intensity of these two bands ratio was lower than for DOX. And as mentioned before, it is interesting to note that no detectable Raman signal was observed after DOX treatment at $1 \mu \mathrm{M}$ (Figure 5A, b-a). No real changes in protein content were highlighted between untreated and SQ-DOX NPs treated cells. Unlike DOX, SQ-DOX NPs treatment did not induce any decrease in the nucleic acids content. However, by increasing the concentration of SQ-DOX NPs to $5 \mu \mathrm{M}$, difference spectrum (c-a, Figure 5B) was marked by very high Raman intensity of bands corresponding to DOX features. In addition, the intensity of $1210 / 1241 \mathrm{~cm}^{-1}$ ratio in difference spectrum (c-a) decreased as compared to (b-a) (Figure 5B). Such decrease suggests that released DOX is intercalated in DNA after hydrolysis.

We then investigated the distribution and the interaction of DOX and SQ-DOX NPs in the cytoplasm of M109 treated cells. Figure 6A and 6B, showed mean Raman spectra of the cytoplasm from untreated and treated cells after $1 \mathrm{~h}$ exposure time to either DOX or SQ-DOX NPs. Raman spectra measured in the cytoplasm of cells treated with $1 \mu \mathrm{M}$ DOX were similar to those of control cells (Figure 6A). Difference spectra (Figure 6A, b-a and c-a) suggested that there were no evident DOX features in the cytoplasm, meaning that DOX was predominantly accumulated in the nucleus. In addition, DOX treatment did not induce 
significant changes in the proteins and lipids cytoplasmic contents. Difference spectra were then calculated for SQ-DOX NPs treatment and analyzed (Figure 6B, b-a, c-a). At $1 \mu \mathrm{M}$ SQDOX NPs, the profile of the difference spectrum (b-a) was similar to that observed in the case of DOX treatment. When the cells were treated with $5 \mu \mathrm{M}$ SQ-DOX, the drug was detected in the cytoplasm (Figure 7B, b-a).

Multivariate statistical analysis (PCA) was performed on two different datasets containing all Raman images obtained from untreated and treated cells with DOX and SQ-DOX treatments at concentration of $5 \mu \mathrm{M}$ for 1 and 5 hours. PCA is used to investigate in more detail the subcellular localization of these drugs. Six PCs, representing 95\% of total variance in original data were selected. Among these components, we have identified two PCs composed of the bands at $1084,1215,1243$, and $1445 \mathrm{~cm}^{-1}$ that could be attributed to the main characteristic bands of DOX. Figure 8 showed these two DOX PCs spectra extracted respectively from the two datasets, PC-Data1 for DOX and PC-Data2 for SQ-DOX NPs treatments. In order to better visualize these peaks, Raman spectra of DOX and SQ-DOX in aqueous solutions were displayed in the same figure. The intensity ratio $1215 / 1243 \mathrm{~cm}^{-1}$ in the spectra related to PCData1 and PC-Data2 were comparable to those of free DOX and SQ-DOX respectively. Pseudo-color scores images associated to these two PCs were reconstructed (Figure 9). White color represents the area where no cellular information was present. Significant differences in the localization of DOX and SQ-DOX NPs can be observed in the subcellular regions. In fact, for both cell lines, the analysis PC-Data1 pseudocolor map showed that the scores related to this component was very low in the cytoplasm and increased in the nucleus meaning that DOX was only localized in the nucleus. The scores increased with the increase of the concentration of DOX treatment. However, when the cells were incubated with SQ-DOX NPs at concentration of $5 \mu \mathrm{M}$ for $1 \mathrm{~h}$, PC-Data2 showed the distribution of the drug in the cytoplasm and the nucleus. In fact, the scores maps showed that the drug was localized into 
cell cytoplasm and nucleus for both cell lines. In addition, PC-Data2 scores were more intense in both two cell lines than those of PC-Data1 meaning that SQ-Dox NPs accumulation was higher than DOX. When the cells were treated with $5 \mu \mathrm{M}$ of SQ-DOX NPs for $5 \mathrm{~h}, \mathrm{PC}-$ Data2 scores showed an increase in the accumulation of the drug mainly in the nucleus. These data were in agreement with those obtained using single point measurements on M109 cell line.

\section{DISCUSSION}

One of the most innovative and recent strategies in nanomedicine was the recent introduction of the "squalenoylation" technology. Such strategy has allowed the emergence of new treatments in cancer (41), neurological disorders (42), pain (43) and inflammation (44). The “squalenoylation" method, initially developed with highly hydrophilic nucleosidic analogues such as the gemcitabine (45-52) has been further extended to more hydrophobic drugs such as paclitaxel(53) or doxorubicin (DOX) (16). In the case of DOX, conjugates were obtained by the covalent linkage of SQ to DOX on the hydroxyl group of 14-C carbon atom (SQ-DOX) allowing the formation of elongated SQ-DOX NPs in water, with a diameter of $\sim 130 \mathrm{~nm}$ and high drug loading $(\sim 57 \%)(16,54)$.

As shown in figure 1 and table 1, DOX was more cytotoxic than SQ-DOX NPs in M109 cells in vitro. In fact, the $\mathrm{IC}_{50}$ values of $\mathrm{DOX}$ were 7 - and 10-times lower than the values corresponding to SQ-DOX under long- and short-term treatment respectively. These data are in agreement with those published earlier on MiaPaCa2 pancreatic carcinoma cells, which suggested that this differential effect was due to the fact that the drug needs to be released to be active (16). To investigate whether such cytotoxic effect was associated to an apoptotic effect, annexin V staining and caspase-3/7 activity were evaluated. Both DOX and SQ-DOX NPs were able to induce apoptosis (Figure 1c and d). As expected, DOX displayed a higher level of apoptosis markers than SQ-DOX NPs. Altogether, cytotoxic and apoptotic data 
suggest that in vitro, DOX is more active than SQ-DOX NPs. However, it is important to note that the main advantage of SQ-DOX NPs lies in their efficacy in vivo where a reduction of blood clearance and urinary excretion was observed together with higher tumor concentration of the drug (16).

As the aim was to investigate the incorporation and the cellular distribution of DOX and SQDOX NPs, we first analyzed such parameters using confocal fluorescence microscopy. As shown in figures 2 and 3, DOX accumulated predominantly in the cell nucleus. The fact that the fluorescence emission remained relatively low resulted from the quenching of the fluorescence emission upon intercalation of DOX in DNA(39). Similarly, a drug fluorescence emission was also observed in the nucleus after treatment with SQ-DOX NPs. At the opposite of DOX treatment, drug fluorescence emission was also observed in the cytoplasm, suggesting that the hydrolysis of SQ-DOX NPs was necessary before the diffusion of DOX into the nucleus. At this stage, confocal fluorescence microscopy analysis did not allow to distinguish between DOX and SQ-DOX NPs in the different cellular compartments. On the other hand, previous quantitative studies have provided evidence that the nuclear uptake of DOX correlated with its cytotoxic effect (39). In order to characterize the different forms of the drugs at the molecular level, particularly in the case of SQ-DOX NPs treatment, we subsequently analyzed their cellular distribution by Raman microspectroscopy.

Raman microspectroscopy allowed the analysis of the cellular drug distribution and the cellular biochemical changes upon treatment with DOX and SQ-DOX NPs. At a concentration of $5 \mu \mathrm{M}$, the intensity of Raman bands of DOX in the nucleus at 1210,1241 $\mathrm{cm}^{-1}$ clearly appeared in the difference spectrum between treated and untreated cells, indicating nuclear incorporation of the drug (Figure 5). Moreover, the intensity of 1210/1241 $\mathrm{cm}^{-1}$ ratio decreased compared to DOX in solution, suggesting the intercalation of DOX in DNA. We have previously reported that this intercalation of DOX between base pairs of DNA 
was characterized by other changes related to the decrease in the intensities of the bands at $1226 \mathrm{~cm}^{-1}$, and $1255 \mathrm{~cm}^{-1}$, and at $1461 \mathrm{~cm}^{-1}$ (25). In addition, DOX treated cells exhibited a decrease in nucleic acid content which is consistent with its mechanism of action, related to DNA synthesis inhibition $(56,57)$. Such mechanisms include the inhibition of topoisomerase II activity upon its binding to DNA in a ternary complex (56). This latter is consequently able to inhibit DNA replication. In addition, the effect of DOX treatment was associated with an increase in the proteins content, which was in agreement with data reported earlier (57).

After $1 \mu \mathrm{M}$ treatment, data showed that Raman bands intensities attributed mainly to DOX were higher in the cell nuclei after SQ-DOX NPs treatment when compared to DOX. Moreover, these bands were observed only in the cytoplasm of cells treated with SQ-DOX NPs. When cells were treated with $5 \mu \mathrm{M}$ SQ-DOX, the intensities of these Raman bands increased markedly both in the cytoplasm and the nucleus. In addition, the intensity of the $1210 / 1244 \mathrm{~cm}^{-1}$ ratio decreased when compared to the treatment at a concentration of $1 \mu \mathrm{M}$, suggesting that a fraction of hydrolyzed SQ-DOX was intercalated between base pairs of DNA. Unlike DOX, SQ-DOX NPs treatment did not induce detectable decrease in the nucleic acids contents, which is in agreement with the lowest cytotoxicity and apoptosis data.

Maksimenko et al. described that the internalization of SQ-DOX into the cells occurred via endocytosis. The intracellular release of DOX from SQ-DOX NPs results from the hydrolysis of the prodrug in lysosomes by esterases as reported earlier (16). The released drug is then incorporated into the nucleus, allowing the induction of its biological effects. Our data clearly show the presence of SQ in the cytoplasm, as it was expected. In fact, the band at $1669 \mathrm{~cm}^{-1}$, which is specific to SQ, was observed in the difference spectrum recorded form the cytoplasm of cells treated with SQ-DOX NPs and non-treated ones (Figure 6B). Interestingly, this band was also detected in the nucleus of M109 cells treated with SQ-DOX NPs, suggesting that the bioconjugate was probably able to diffuse into the nucleus (Figure 5B). We then asked 
whether this observation could help to understand the discrepancy between the drug fluorescence emission data observed in the nucleus and and its biological effects. We thus analyzed the interaction of SQ-DOX molecules with DNA in solution using surface enhanced Raman scattering (SERS) to verify if SQ-DOX was able (or not) to intercalate into the DNA. SERS spectra of SQ-DOX alone and in the presence of DNA with various ratios were measured. As shown in supplementary Figure S1 and at the opposite of DOX, the comparison between spectra of SQ-DOX, free and complexed to DNA at different molar ratio, did not show any changes in the markers of DNA intercalation.. In other words, DNA intercalation should only occur in the case of released DOX after SQ-DOX hydrolysis. This finding could explain the lower cytoxicity and apoptosis effects in the case of SQ-DOX NPs treatment. In fact, the Raman signal of the drug in the nucleus (Figure 5 and 8) could be a combination of DOX and SQ-DOX spectral features but only the fraction of DOX released from SQ-DOX could intercalate into the DNA (Figure 5B), as confirmed in part by the relative decrease in the intensity $1210 / 1244 \mathrm{~cm}^{-1}$ ratio (Figure 5B and 8). After $5 \mathrm{~h}$ treatment with SQ-DOX at 5 $\mu \mathrm{M}$, the Raman spectral features showed a higher $1210 / 1244 \mathrm{~cm}^{-1}$ ratio in the nucleus, suggesting a lowest fraction of the intercalated form of DOX and a higher fraction of the nonhydrolyzed form of SQ-DOX (Figure 7a).

\section{CONCLUSION}

This study demonstrated the potential of Raman spectroscopy as a label free technique for the in vitro characterization of the chemotherapeutic agents and their prodrug forms in single living cancer cell. Our data provided simultaneous information on the detection of the different forms of DOX and SQ-DOX NPs, and the identification of biochemical changes. Distinct Raman spectroscopic markers of these chemotherapeutic agents were identified and used to understand the mechanisms involved in the efficacy of the drugs in vitro. In 
conclusion, this study brings new insights to the cellular characterization of anticancer drugs at the molecular level, particularly in the field of nanomedicine.

\section{ACKNOWLEDGEMENTS}

The authors would like to thank the Platform of Cellular and Tissular Imaging (PICT) for the equipment availability.

\section{AUTHOR CONTRIBUTIONS}

PC, HM and AB: Conception and design; FD, BS, AA, MC and AM: synthesis and characterization of nanoparticles SQ-DOX; HR, LVG, AA, and AB: Methodology and data acquisition ; HR, AA, HM and AB: Data analysis and manuscript writing; SM, DD, and PC: Discussion and revision.

Disclosure Statement: PC is the founder of Squal Pharma, a start-up dedicated to the development of squalenoylated nanomedicines. All other authors have nothing to disclose.

Availability of data and materials: All data generated or analyzed during this study are included in this published article [and its supplementary information files]. If not, they are available from the corresponding author on reasonable request.

Funding: This research did not receive any specific grant from funding agencies in the public, commercial, or not-for-profit sectors.

\section{REFERENCES}

1. Higgins GS, O'Cathail SM, Muschel RJ, McKenna WG. Drug radiotherapy combinations: review of previous failures and reasons for future optimism. Cancer Treat Rev. 2015 Feb;41(2):105-13. 
2. Tacar O, Sriamornsak P, Dass CR. Doxorubicin: an update on anticancer molecular action, toxicity and novel drug delivery systems. J Pharm Pharmacol. 2013 Feb;65(2):157-70.

3. Arcamone F. Properties of antitumor anthracyclines and new developments in their application: Cain memorial award lecture. Cancer Res. 1985 Dec;45(12 Pt 1):5995-9.

4. Meredith A-M, Dass CR. Increasing role of the cancer chemotherapeutic doxorubicin in cellular metabolism. J Pharm Pharmacol. 2016 Jun;68(6):729-41.

5. Thorn CF, Oshiro C, Marsh S, Hernandez-Boussard T, McLeod H, Klein TE, et al. Doxorubicin pathways: pharmacodynamics and adverse effects. Pharmacogenetics and Genomics. 2011 Jul;21(7):440-6.

6. Yang F, Teves SS, Kemp CJ, Henikoff S. Doxorubicin, DNA torsion, and chromatin dynamics. Biochimica et Biophysica Acta (BBA) - Reviews on Cancer. 2014 Jan;1845(1):84-9.

7. Pommier Y, Leo E, Zhang H, Marchand C. DNA Topoisomerases and Their Poisoning by Anticancer and Antibacterial Drugs. Chemistry \& Biology. 2010 May;17(5):421-33.

8. Tan HH, Porter AG. DNA methyltransferase $\mathrm{I}$ is a mediator of doxorubicin-induced genotoxicity in human cancer cells. Biochemical and Biophysical Research Communications. 2009 May;382(2):462-7.

9. Yokochi T. Doxorubicin Inhibits DNMT1, Resulting in Conditional Apoptosis. Molecular Pharmacology. 2004 Aug 31;66(6):1415-20.

10. Carvalho C, Santos R, Cardoso S, Correia S, Oliveira P, Santos M, et al. Doxorubicin: The Good, the Bad and the Ugly Effect. Current Medicinal Chemistry. 2009 Sep $1 ; 16(25): 3267-85$. 
11. Octavia Y, Tocchetti CG, Gabrielson KL, Janssens S, Crijns HJ, Moens AL. Doxorubicin-induced cardiomyopathy: From molecular mechanisms to therapeutic strategies. Journal of Molecular and Cellular Cardiology. 2012 Jun;52(6):1213-25.

12. Brigger I, Dubernet C, Couvreur P. Nanoparticles in cancer therapy and diagnosis. Advanced Drug Delivery Reviews. 2002 Sep;54(5):631-51.

13. Cho K, Wang X, Nie S, Chen Z, Shin DM. Therapeutic Nanoparticles for Drug Delivery in Cancer. Clinical Cancer Research. 2008 Mar 1;14(5):1310-6.

14. Horcajada P, Chalati T, Serre C, Gillet B, Sebrie C, Baati T, et al. Porous metal-organicframework nanoscale carriers as a potential platform for drug delivery and imaging. Nature Materials. 2010 Feb;9(2):172-8.

15. Shi J, Kantoff PW, Wooster R, Farokhzad OC. Cancer nanomedicine: progress, challenges and opportunities. Nature Reviews Cancer. 2016 Nov 11;17(1):20-37.

16. Maksimenko A, Dosio F, Mougin J, Ferrero A, Wack S, Reddy LH, et al. A unique squalenoylated and nonpegylated doxorubicin nanomedicine with systemic longcirculating properties and anticancer activity. Proc Natl Acad Sci USA. 2014 Jan 14;111(2):E217-226.

17. Bae YH, Park K. Targeted drug delivery to tumors: myths, reality and possibility. J Control Release. 2011 Aug 10;153(3):198-205.

18. Mallidis C, Sanchez V, Wistuba J, Wuebbeling F, Burger M, Fallnich C, et al. Raman microspectroscopy: shining a new light on reproductive medicine. Hum Reprod Update. 2014 Jun;20(3):403-14.

19. Neugebauer U, Rösch P, Popp J. Raman spectroscopy towards clinical application: drug monitoring and pathogen identification. International Journal of Antimicrobial Agents. 2015 Dec;46:S35-9. 
20. Gala de Pablo J, Armistead FJ, Peyman SA, Bonthron D, Lones M, Smith S, et al. Biochemical fingerprint of colorectal cancer cell lines using label-free live single-cell Raman spectroscopy. Journal of Raman Spectroscopy. 2018 Aug;49(8):1323-32.

21. Guo J, Cai W, Du B, Qian M, Sun Z. Raman spectroscopic investigation on the interaction of malignanthepatocytes with doxorubicin. Biophysical Chemistry. 2009 Mar;140(1-3):57-61.

22. Schie IW, Alber L, Gryshuk AL, Chan JW. Investigating drug induced changes in single, living lymphocytes based on Raman micro-spectroscopy. The Analyst. 2014;139(11):2726-33.

23. Short KW, Carpenter S, Freyer JP, Mourant JR. Raman Spectroscopy Detects Biochemical Changes Due to Proliferation in Mammalian Cell Cultures. Biophys J. 2005 Jun;88(6):4274-88.

24. Swain RJ, Stevens MM. Raman microspectroscopy for non-invasive biochemical analysis of single cells. Biochem Soc Trans. 2007 Jun;35(Pt 3):544-9.

25. Beljebbar A, Sockalingum GD, Angiboust JF, Manfait M. Comparative FT SERS, resonance Raman and SERRS studies of doxorubicin and its complex with DNA. Spectrochimica Acta Part A: Molecular and Biomolecular Spectroscopy. 1995 Nov;51(12):2083-90.

26. Byrne HJ, Bonnier F, Casey A, Maher M, McIntyre J, Efeoglu E, et al. Advancing Raman microspectroscopy for cellular and subcellular analysis: towards in vitro highcontent spectralomic analysis. Appl Opt. 2018 Aug 1;57(22):E11-9.

27. Das G, Nicastri A, Coluccio ML, Gentile F, Candeloro P, Cojoc G, et al. FT-IR, Raman, RRS measurements and DFT calculation for doxorubicin. Microscopy Research and Technique. 2010;NA-NA. 
28. Farhane Z, Bonnier F, Byrne HJ. An in vitro study of the interaction of the chemotherapeutic drug Actinomycin D with lung cancer cell lines using Raman microspectroscopy. J Biophotonics. 2018 Jan;11(1).

29. Farhane Z, Bonnier F, Howe O, Casey A, Byrne HJ. Doxorubicin kinetics and effects on lung cancer cell lines using in vitro Raman micro-spectroscopy: binding signatures, drug resistance and DNA repair. J Biophotonics. 2018 Jan;11(1).

30. Manfait M, Alix AJ, Jeannesson P, Jardillier JC, Theophanides T. Interaction of adriamycin with DNA as studied by resonance Raman spectroscopy. Nucleic Acids Res. 1982 Jun 25;10(12):3803-16.

31. Moritz TJ, Taylor DS, Krol DM, Fritch J, Chan JW. Detection of doxorubicin-induced apoptosis of leukemic T-lymphocytes by laser tweezers Raman spectroscopy. Biomedical Optics Express. 2010 Nov 1;1(4):1138.

32. Lê LMM, Berge M, Tfayli A, Zhou J, Prognon P, Baillet-Guffroy A, et al. Rapid discrimination and quantification analysis of five antineoplastic drugs in aqueous solutions using Raman spectroscopy. European Journal of Pharmaceutical Sciences. 2018 Jan;111:158-66.

33. Birech Z, Mwangi PW, Bukachi F, Mandela KM. Application of Raman spectroscopy in type 2 diabetes screening in blood using leucine and isoleucine amino-acids as biomarkers and in comparative anti-diabetic drugs efficacy studies. PLoS ONE. 2017;12(9):e0185130.

34. Bourget P, Amin A, Vidal F, Merlette C, Troude P, Baillet-Guffroy A. The contribution of Raman spectroscopy to the analytical quality control of cytotoxic drugs in a hospital environment: eliminating the exposure risks for staff members and their work environment. Int J Pharm. 2014 Aug 15;470(1-2):70-6. 
35. Nawaz H, Bonnier F, Knief P, Howe O, Lyng FM, Meade AD, et al. Evaluation of the potential of Raman microspectroscopy for prediction of chemotherapeutic response to cisplatin in lung adenocarcinoma. The Analyst. 2010;135(12):3070.

36. Wolthuis R, Bakker Schut TC, Caspers PJ, Buschman HPJ, Romer TJ, Bruining HA, et al. In Fluorescent and Luminescent Probes for Biological Activity. Mason, WT, Ed. 1999;433-55.

37. Barnes RJ, Dhanoa MS, Lister SJ. Standard Normal Variate Transformation and Detrending of Near-Infrared Diffuse Reflectance Spectra. Appl Spectrosc, AS. 1989 May $1 ; 43(5): 772-7$.

38. Gigli M, Rasoanaivo TW, Millot JM, Jeannesson P, Rizzo V, Jardillier JC, et al. Correlation between growth inhibition and intranuclear doxorubicin and 4'-deoxy-4'iododoxorubicin quantitated in living K562 cells by microspectrofluorometry. Cancer Res. 1989 Feb 1;49(3):560-4.

39. Morjani H, Millot JM, Belhoussine R, Sebille S, Manfait M. Anthracycline subcellular distribution in human leukemic cells by microspectrofluorometry: factors contributing to drug-induced cell death and reversal of multidrug resistance. Leukemia. 1997 $\mathrm{Jul} ; 11(7): 1170-9$.

40. Chun HJ, Weiss TL, Devarenne TP, Laane J. Vibrational spectra and DFT calculations of squalene. Journal of Molecular Structure. 2013 Jan;1032:203-6.

41. Kotelevets L, Chastre E, Caron J, Mougin J, Bastian G, Pineau A, et al. A SqualeneBased Nanomedicine for Oral Treatment of Colon Cancer. Cancer Research. 2017 Jun 1;77(11):2964-75.

42. Gaudin A, Yemisci M, Eroglu H, Lepetre-Mouelhi S, Turkoglu OF, Dönmez-Demir B, et al. Squalenoyl adenosine nanoparticles provide neuroprotection after stroke and spinal cord injury. Nature Nanotechnology. 2014 Dec;9(12):1054-62. 
43. Feng J, Lepetre-Mouelhi S, Gautier A, Mura S, Cailleau C, Coudore F, et al. A new painkiller nanomedicine to bypass the blood-brain barrier and the use of morphine. Science Advances. 2019 Feb;5(2):eaau5148.

44. Dormont F, Brusini R, Cailleau C, Reynaud F, Peramo A, Gendron A, et al. Squalenebased multidrug nanoparticles for improved mitigation of uncontrolled inflammation in rodents. Science Advances. 2020 Jun;6(23):eaaz5466.

45. Couvreur P, Stella B, Reddy LH, Hillaireau H, Dubernet C, Desmaële D, et al. Squalenoyl Nanomedicines as Potential Therapeutics. Nano Letters. 2006 Nov;6(11):2544-8.

46. Desmaële D, Gref R, Couvreur P. Squalenoylation: A generic platform for nanoparticular drug delivery. Journal of Controlled Release. 2012 Jul;161(2):609-18.

47. Reddy LH, Renoir J-M, Marsaud V, Lepetre-Mouelhi S, Desmaële D, Couvreur P. Anticancer Efficacy of Squalenoyl Gemcitabine Nanomedicine on 60 Human Tumor Cell Panel and on Experimental Tumor. Molecular Pharmaceutics. 2009 Oct $5 ; 6(5): 1526-35$.

48. Reddy LH, Khoury H, Paci A, Deroussent A, Ferreira H, Dubernet C, et al. Squalenoylation Favorably Modifies the in Vivo Pharmacokinetics and Biodistribution of Gemcitabine in Mice. Drug Metabolism and Disposition. 2008 Aug;36(8):1570-7.

49. Reddy LH, Marque P-E, Dubernet C, Mouelhi S-L, Desmaële D, Couvreur P. Preclinical Toxicology (Subacute and Acute) and Efficacy of a New Squalenoyl Gemcitabine Anticancer Nanomedicine. Journal of Pharmacology and Experimental Therapeutics. 2008 May;325(2):484-90.

50. Reddy LH, Dubernet C, Mouelhi SL, Marque PE, Desmaele D, Couvreur P. A new nanomedicine of gemcitabine displays enhanced anticancer activity in sensitive and resistant leukemia types. Journal of Controlled Release. 2007 Dec;124(1-2):20-7. 
51. Sobot D, Mura S, Rouquette M, Vukosavljevic B, Cayre F, Buchy E, et al. Circulating Lipoproteins: A Trojan Horse Guiding Squalenoylated Drugs to LDL-Accumulating Cancer Cells. Mol Ther. 2017 05;25(7):1596-605.

52. Sobot D, Mura S, Yesylevskyy SO, Dalbin L, Cayre F, Bort G, et al. Conjugation of squalene to gemcitabine as unique approach exploiting endogenous lipoproteins for drug delivery. Nat Commun. 2017 30;8:15678.

53. Caron J, Maksimenko A, Wack S, Lepeltier E, Bourgaux C, Morvan E, et al. Improving the Antitumor Activity of Squalenoyl-Paclitaxel Conjugate Nanoassemblies by Manipulating the Linker between Paclitaxel and Squalene. Advanced Healthcare Materials. 2013 Jan;2(1):172-85.

54. Mougin J, Yesylevskyy SO, Bourgaux C, Chapron D, Michel J-P, Dosio F, et al. Stacking as a Key Property for Creating Nanoparticles with Tunable Shape: The Case of Squalenoyl-Doxorubicin. ACS Nano. 2019 Nov 26;13(11):12870-9.

55. Nawaz H, Garcia A, Meade AD, Lyng FM, Byrne HJ. Raman micro spectroscopy study of the interaction of vincristine with A549 cells supported by expression analysis of bcl2 protein. Analyst. 2013;138(20):6177.

56. Komiyama T, Oki T, Inui $\mathrm{T}$. Interaction of new anthracycline antibiotics with DNA. Effects on nucleic acid synthesis and binding to DNA. Biochimica et Biophysica Acta (BBA) - Gene Structure and Expression. 1983 May 20;740(1):80-7.

57. Farhane Z, Bonnier F, Byrne HJ. Monitoring doxorubicin cellular uptake and trafficking using in vitro Raman microspectroscopy: short and long time exposure effects on lung cancer cell lines. Analytical and Bioanalytical Chemistry. 2017 Feb;409(5):1333-46. 


\section{Legend figure}

Figure 1: Antitumor activity of DOX and SQ-DOX on M109 cell growth (a and b) and apoptosis (c and d). For cell growth inhibition, cells were treated with concentrations ranging from $0.1 \mathrm{nM}$ to $1 \mu \mathrm{M}$ for a) $72 \mathrm{~h}$ time exposure and b) $1 \mathrm{~h}$ treatment and $72 \mathrm{~h}$ post-incubation after washing. For apoptosis, flow cytometry analysis of (c) Annexin V and (d) Caspase 3/7 expressed by the percentage of M109 apoptotic positive cells assessed using the Muse Annexin V and Caspase 3/7 assay kit. Cell growth rate is expressed as percentage compared to untreated cells control; error bars indicating standard deviation of three duplicated independent measurements. For apoptosis, values represent the mean \pm SEM of three independent experiments ( $\mathrm{n}=3$, Mann \& Whitney test).

Figure 2: Fluorescence microscopy images of M109 and MDA-MB-231 cells treated with DOX and SQ-DOX at concentrations of $1 \mu \mathrm{M}(1 \mathrm{~h})$ and $5 \mu \mathrm{M}$ (1 and 5hrs). These imges showed the intracellular uptake of free DOX and SQ-DOX NPs (in red) and its merge with the bright field image of the corresponding cell $(\mathrm{x} 63$, scale bar $=10 \mu \mathrm{m})$.

Figure 3: Quantification the nuclear accumulation of DOX and SQ-DOX at concentrations of $1 \mu \mathrm{M}$ and $5 \mu \mathrm{M}$ from the analysis of fluorescence images using ImageJ software. Regions-ofinterest (ROIs) were selected on each cell nucleus (M109 and MDA-MB-231) treated with DOX and SQ-DOX NPs. The average fluorescence intensity was calculated for each drug at 1 $\mathrm{h}$ and $5 \mathrm{~h}$ exposition time.

Figure 4: Chemical structure of a) DOX, b) SQ, c) SQ-DOX, and d) their Raman spectra in solutions.

Figure 5: Mean Raman spectra measured on untreated cell nucleus (a) and nucleus treated for $1 \mathrm{~h}$ with DOX (panel A) and SQ-DOX (panel B) with concentrations of: b) $1 \mu \mathrm{M}$, and c) 5 $\mu$ M. 10 spectra were measured on each cell nucleus with an acquisition time of 10 seconds in the fingerprint region $570-1800 \mathrm{~cm}^{-1}$. The shaded areas represent the respective standard deviations. Difference spectra (b-a, c-a) were obtained by subtracting Raman spectra treated cell with concentration of $1 \mu \mathrm{M}$ and $5 \mu \mathrm{M}$ from untreated cells.

Figure 6: Mean Raman spectra measured on untreated cell cytoplasm (a) and cytoplasm treated for $1 \mathrm{~h}$ with DOX (panel A) and SQ-DOX (panel B) with concentrations of: b) $1 \mu \mathrm{M}$, c) $5 \mu \mathrm{M}$. 10 spectra were measured on each cell cytoplasm with an acquisition time of 10 seconds in the fingerprint region $570-1800 \mathrm{~cm}^{-1}$. The shaded areas represent the respective standard deviations. Difference spectra (b-a, c-a) were obtained by subtracting Raman spectra treated cell with concentration of $1 \mu \mathrm{M}$ and $5 \mu \mathrm{M}$ from untreated cells.

Figure 7: Mean Raman spectra measured on nucleus (panel A) and cytoplasm (pane B) on untreated cell (a) and treated $5 \mathrm{~h}$ with SQ-DOX at concentration of $5 \mu \mathrm{M}$ (b). Difference spectra (b-a) was obtained by subtracting Raman spectra treated cell with concentration of 5 $\mu \mathrm{M}$ from untreated cells. The shaded areas represent the respective standard deviations.

Figure 8: Comparison between the two PCs (PC-Data1 and PC-Data2) potentially attributed to DOX or SQ-DOX and Raman spectra of DOX and SQ-DOX in aqueous solutions.

Figure 9: Pseudo-color scores images associated to PC-Data1 and PC-Data2 from M109 and MDA-MB-231 cells treated with DOX and SQ-DOX treatments at concentration of $5 \mu \mathrm{M}$ for 
1 and 5 hours. These maps displayed significant differences in the localization of these drugs in the subcellular regions.

a

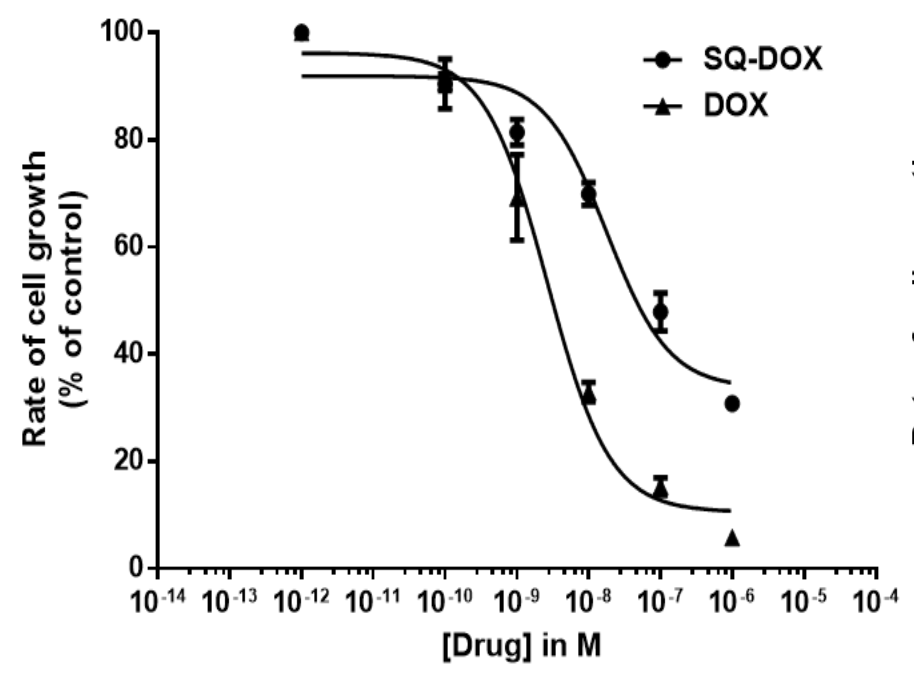

c

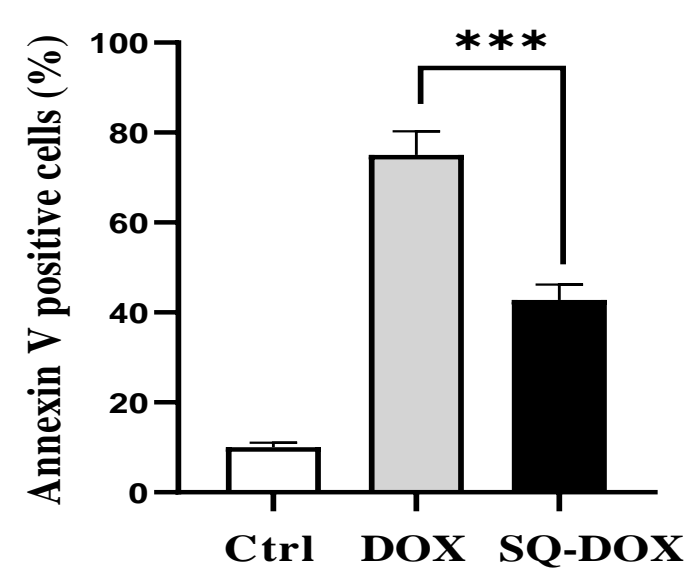

b

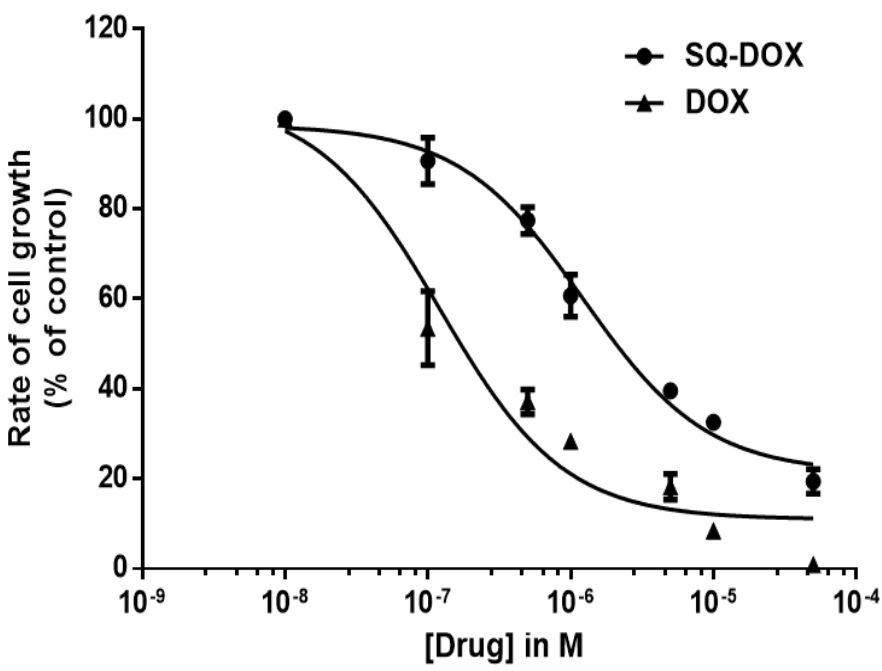

d

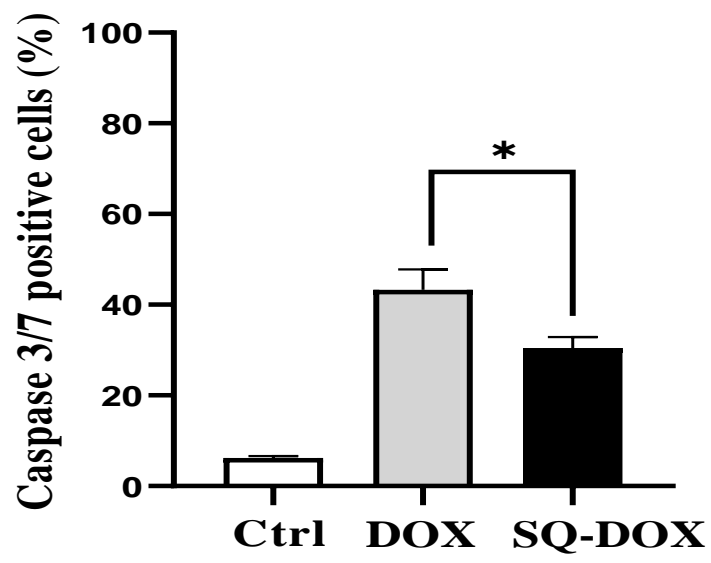


M109

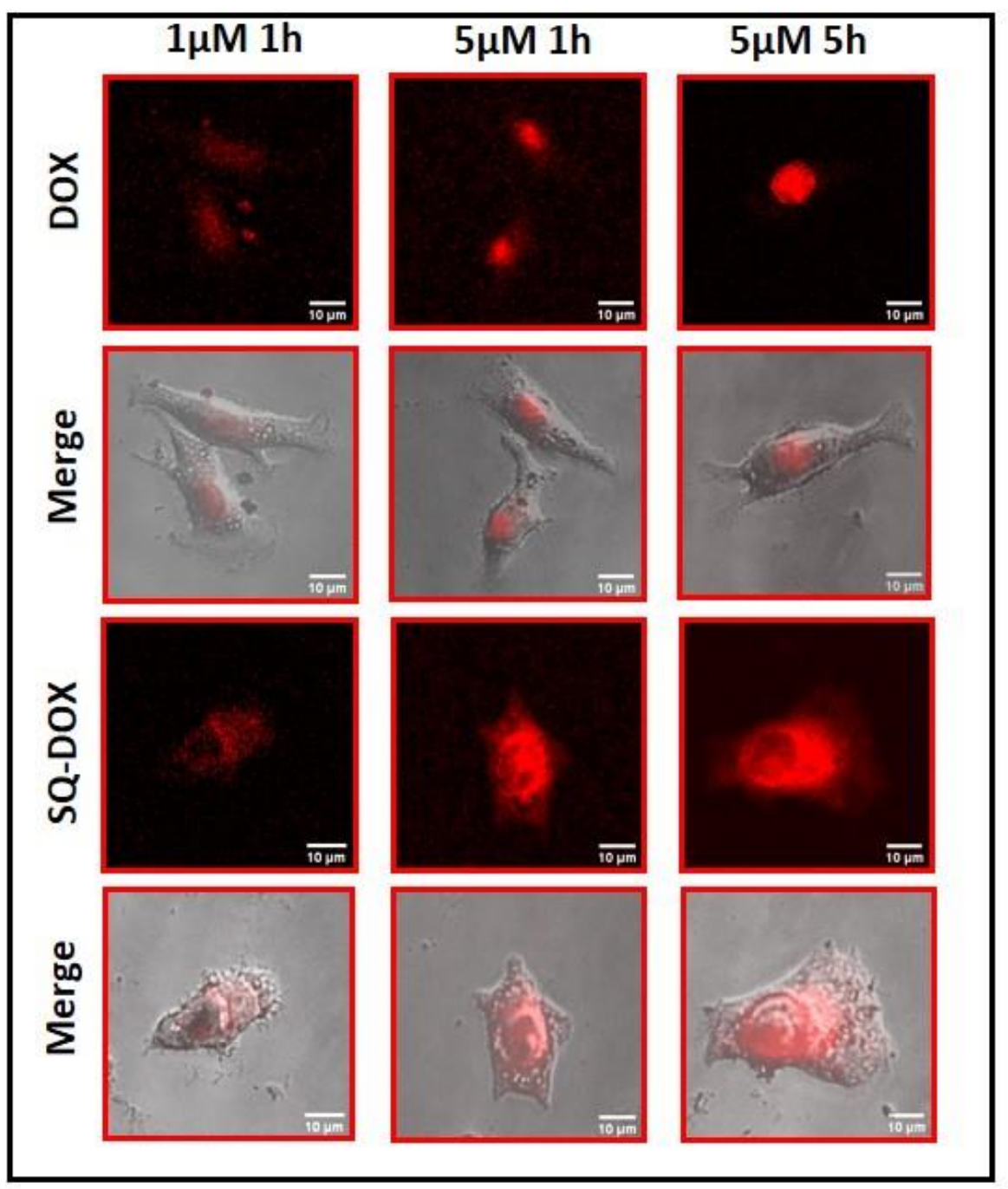

MDA-MB-231

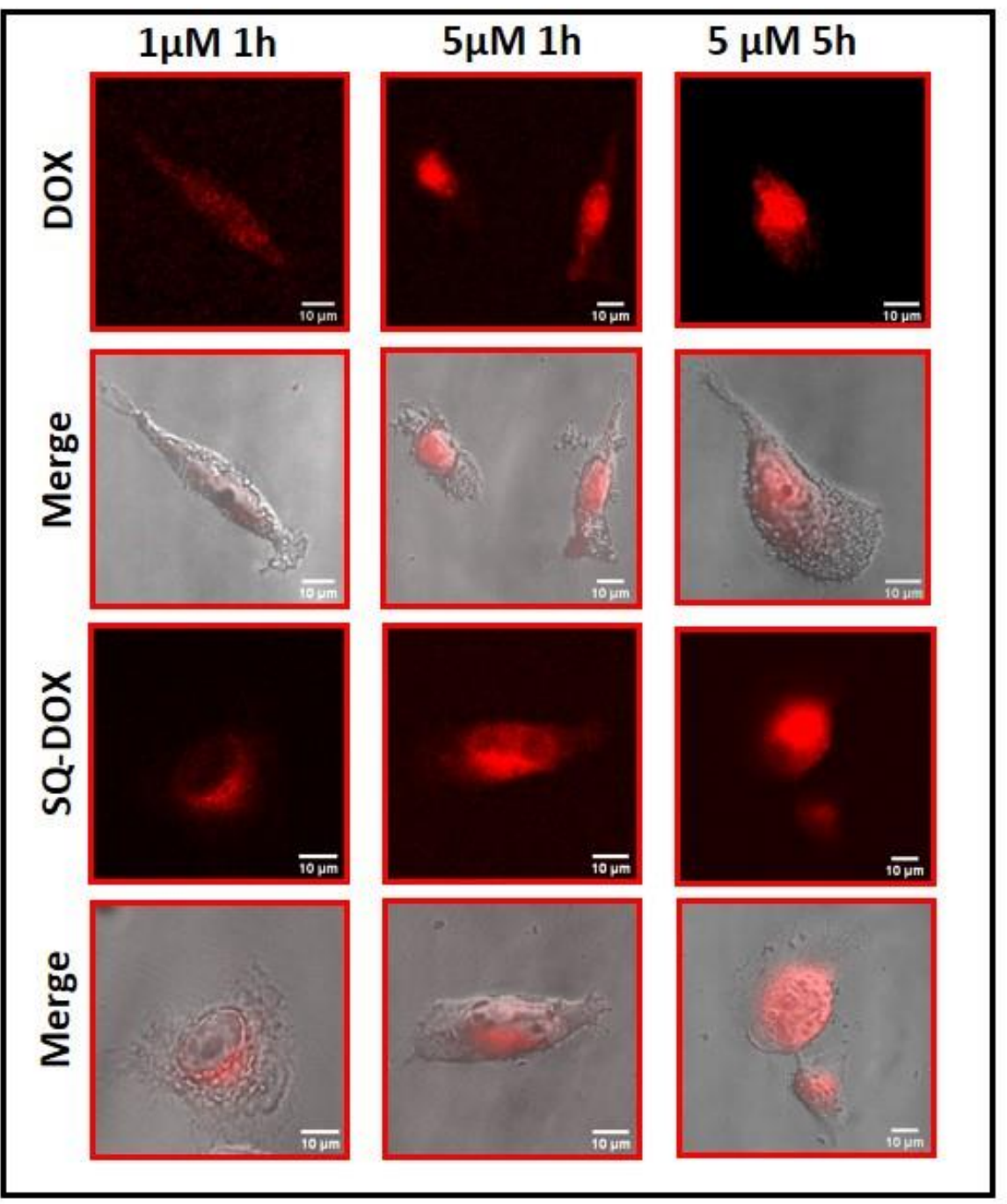

Figure 2 

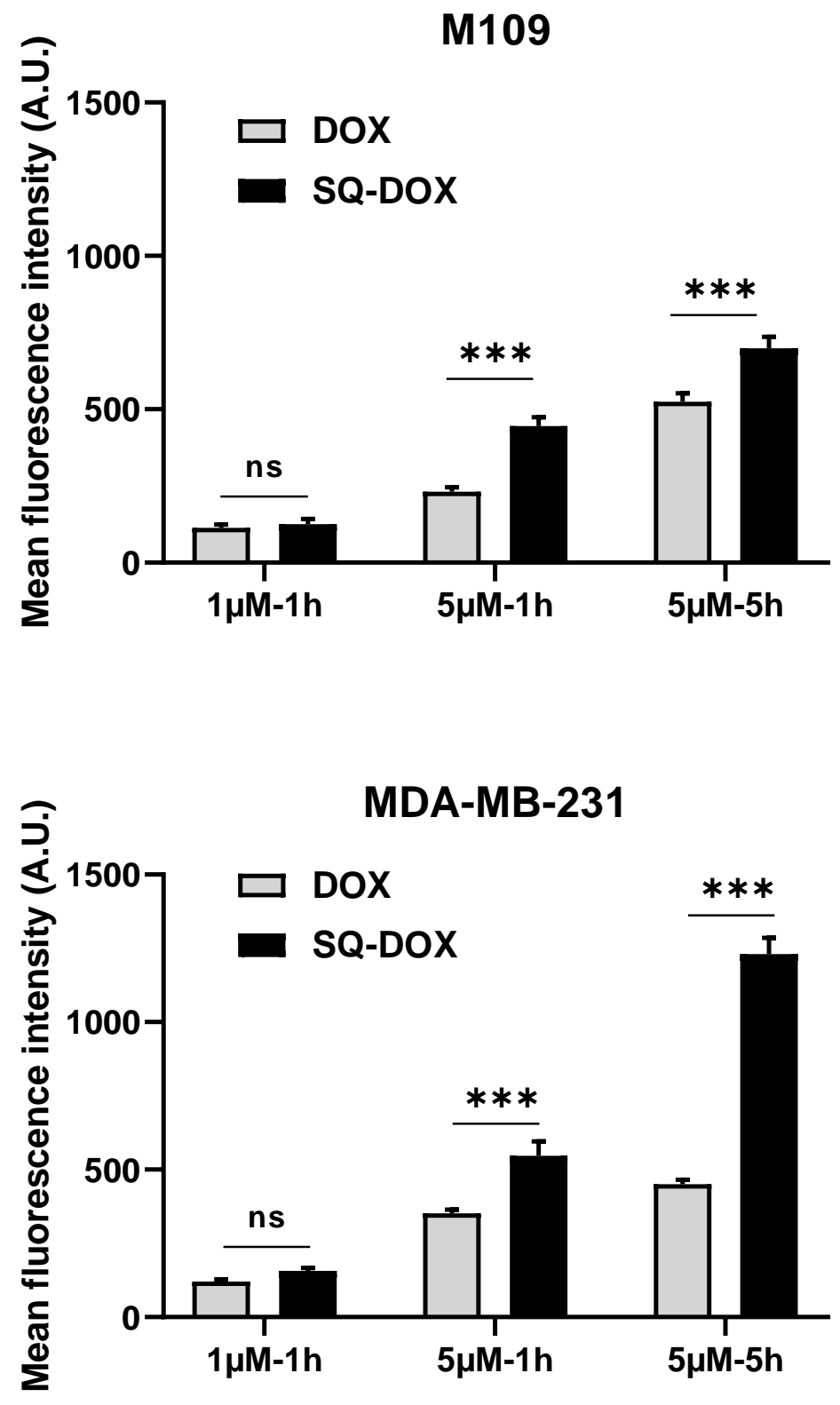

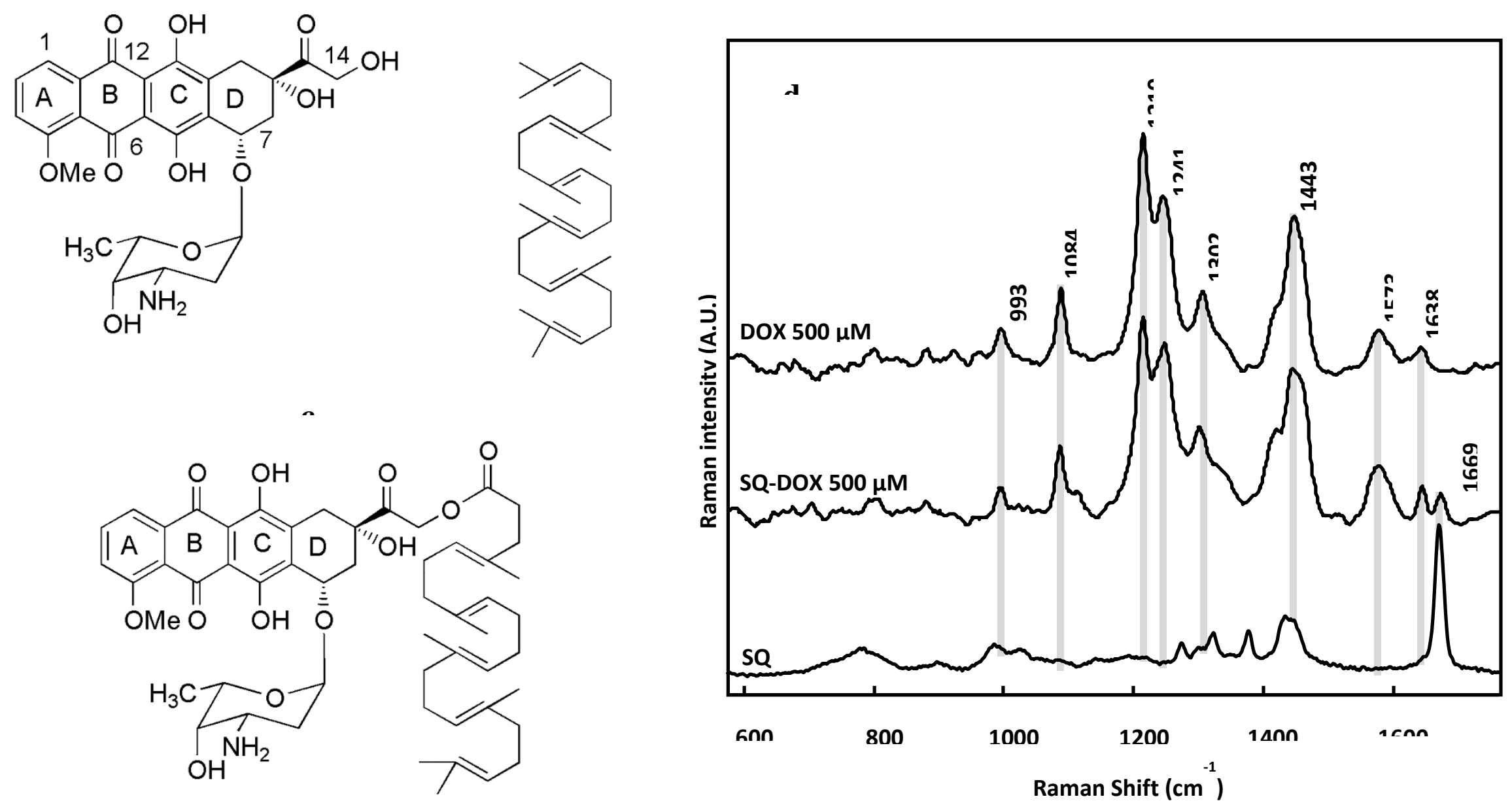

Figure 4 

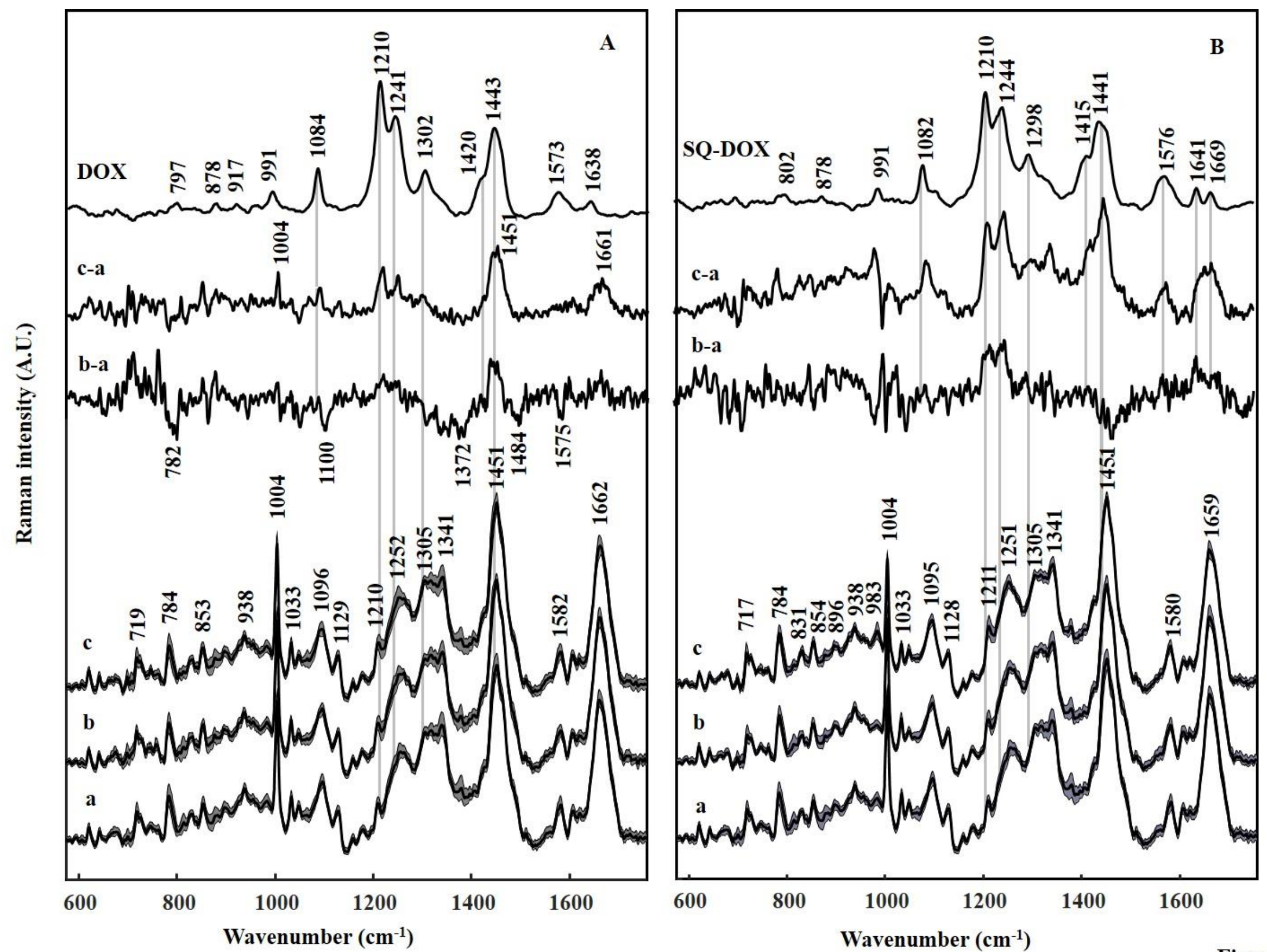

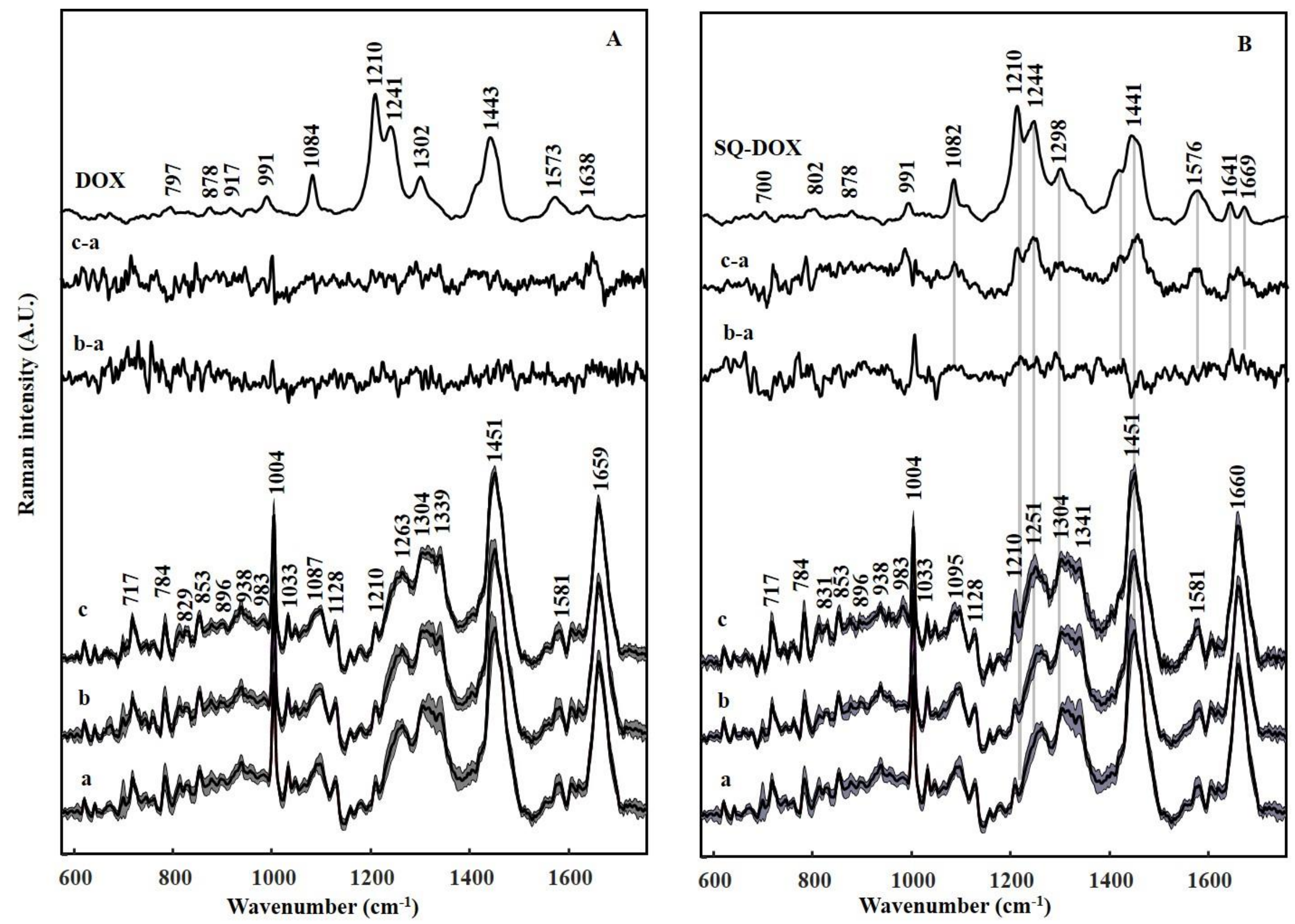

Figure 6 

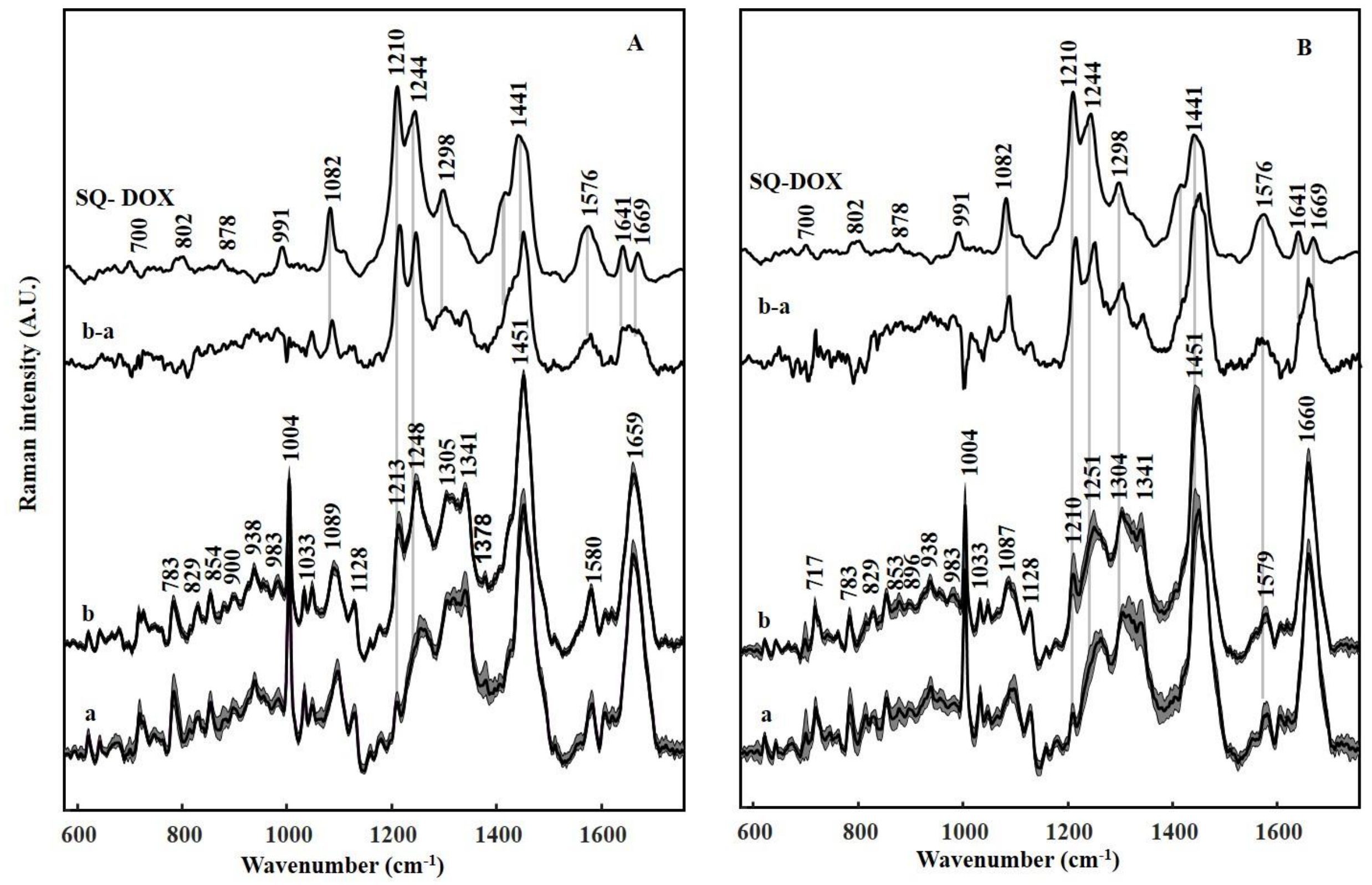

Figure 7 



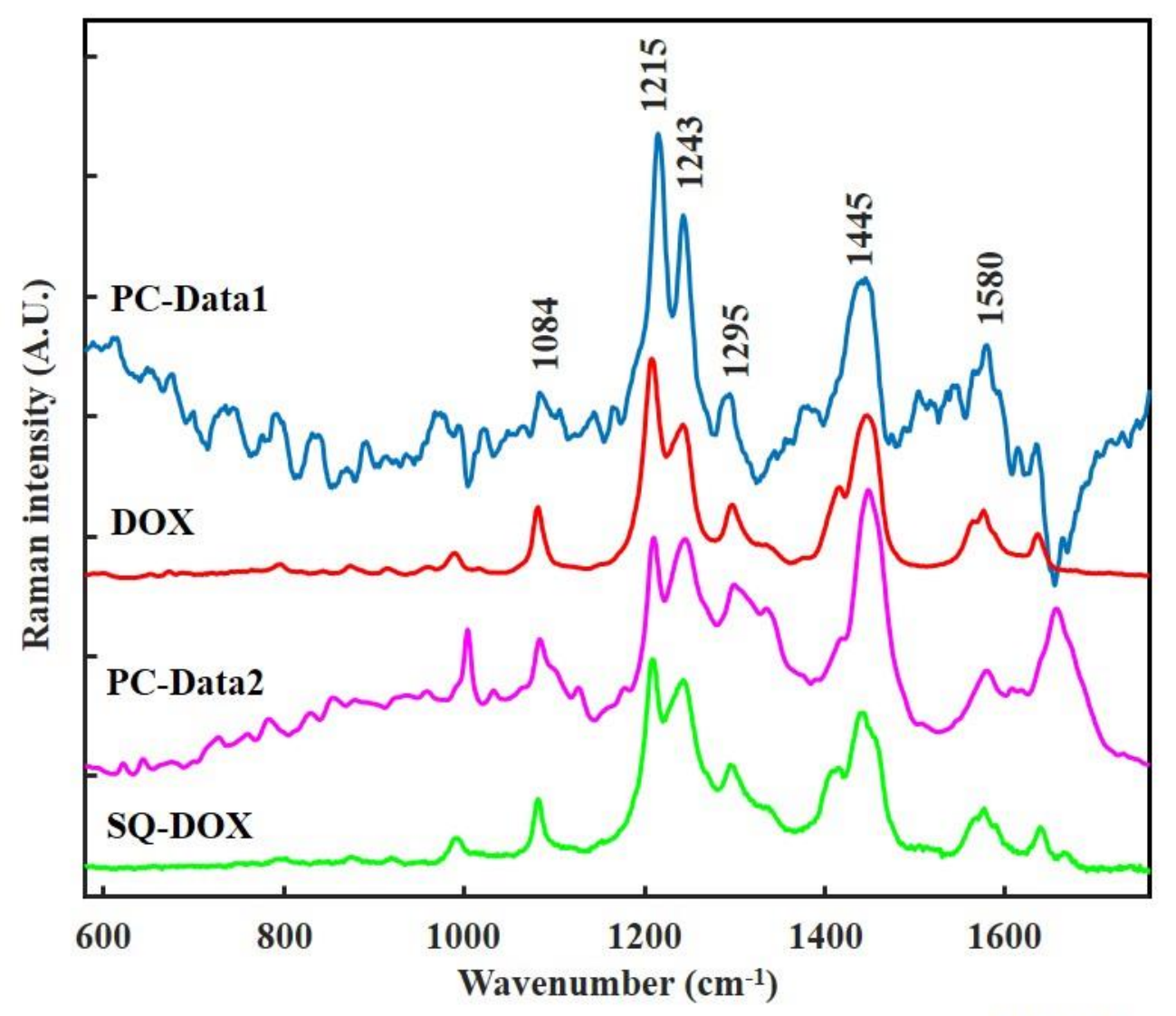

Figure 8 
M109

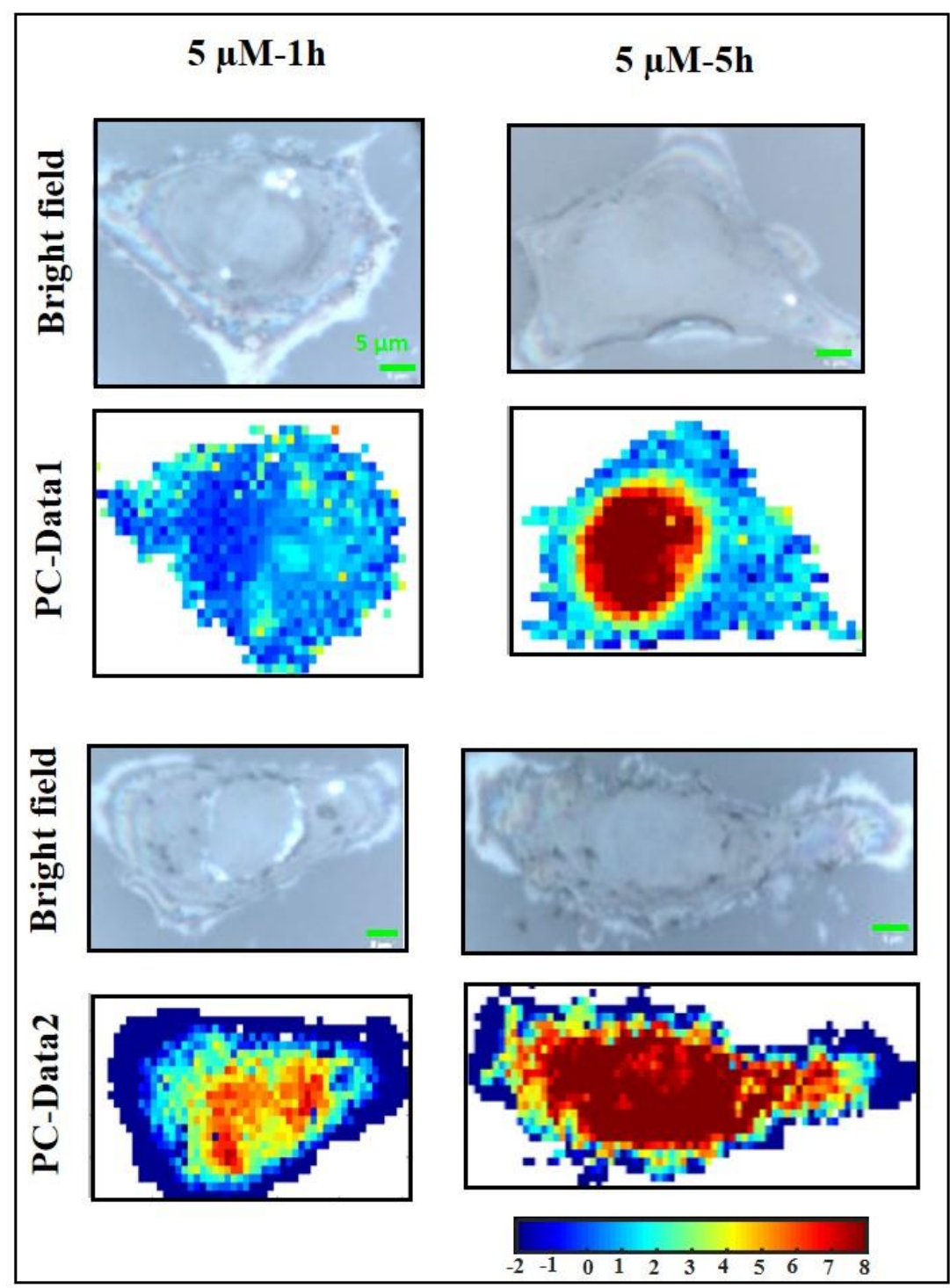

MDA-MB-231

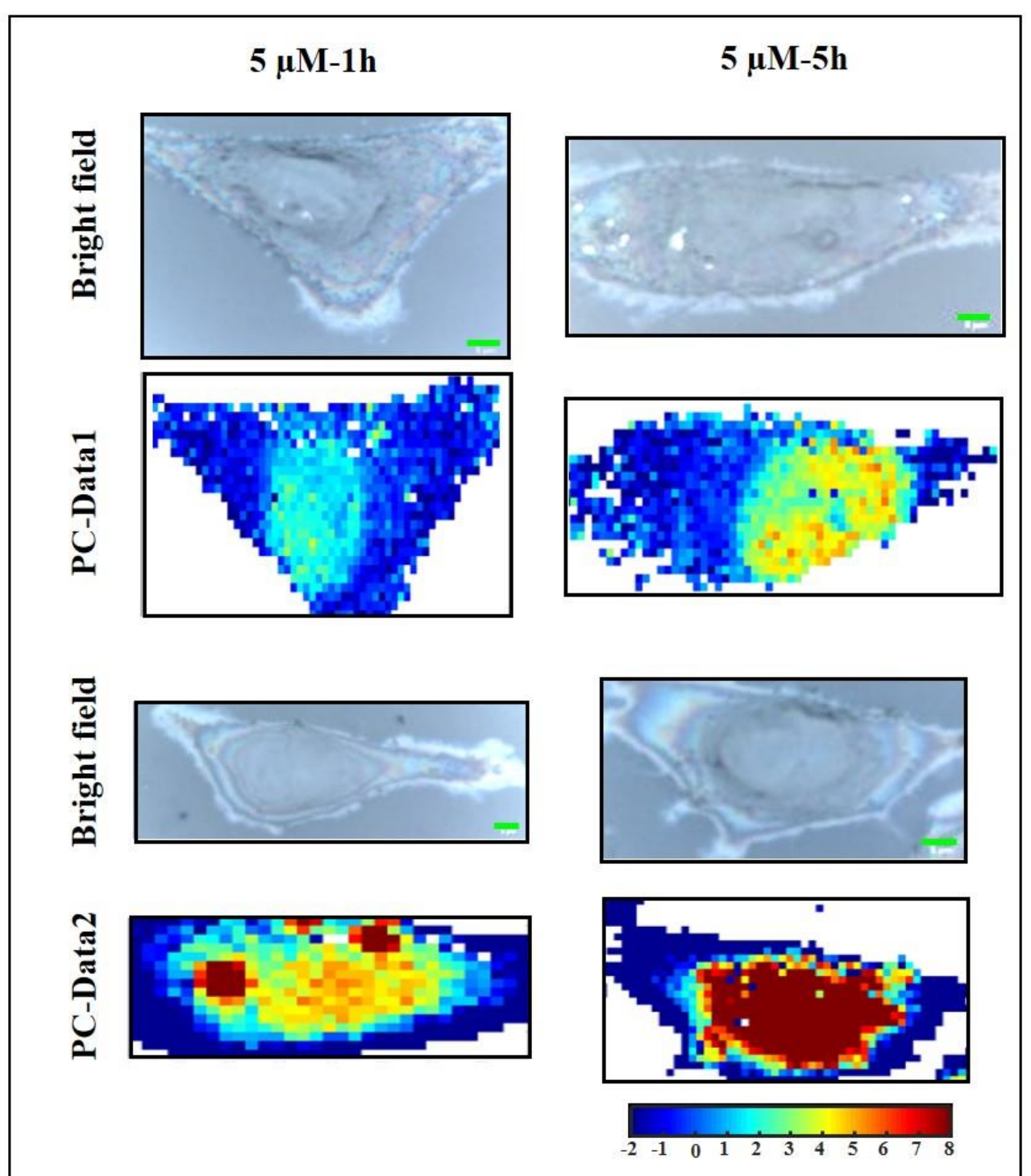

Figure 9 
Supplementary information 1

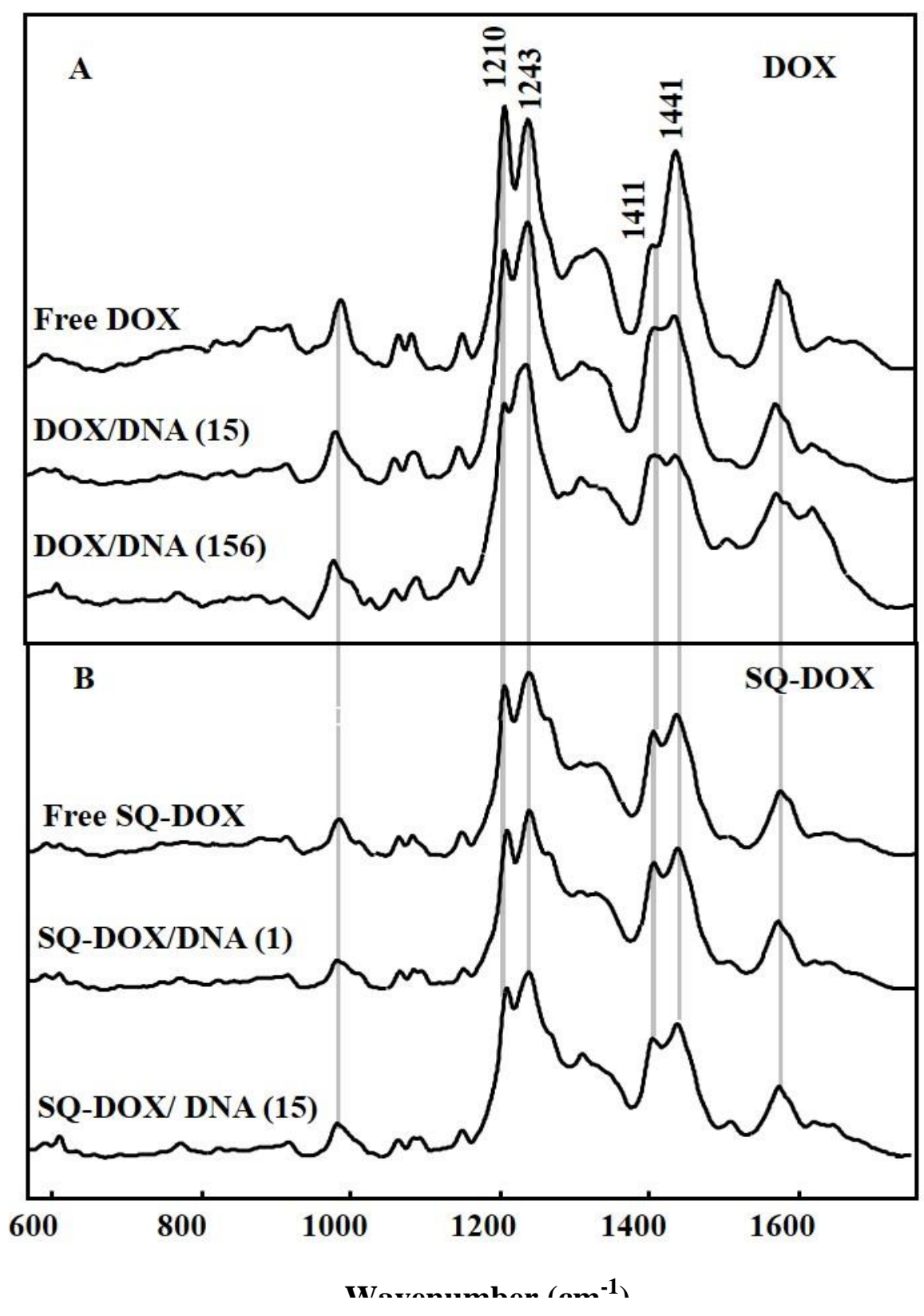

Figure S1: Surface enhanced Raman spectra of DOX (panel A) and SQ-DOX (panel B), and their complexes with calf-thymus DNA. DOX/DNA complex: ratio 1 molecule of drug for 15 and 156 base pairs. SQ-DOX/DNA complex: ratio 1 molecule of drug for 1 and 15 base pairs of DNA. Concentration of the free DOX $5 \times 1^{-7} \mathbf{M}$ and SQ-DOX $10^{-5} \mathbf{M}$; excitation wavelength: $532 \mathrm{~nm} ; 20$ seconds accumulation time. Absolute concentration of the drug/DNA complex in the hydrosol was adjusted to have a spectrum of quality comparable to that of free drugs. 